\title{
Zelulosa biopolimeroaren propietate molekularrak argiratzen
}

\section{(Unraveling the molecular properties of the cellulose biopolymer)}

\author{
Imanol Usabiaga*1,2, Maider Parra, ${ }^{1,2}$, Aran Insausti ${ }^{1,2}$, Ander Camiruaga $^{1}$, \\ Antonio Veloso ${ }^{1}$, José Andrés Fernández ${ }^{1}$ \\ ${ }^{1}$ Kimika Fisikoa Saila, Zientzia eta Teknologia Fakultatea, \\ Euskal Herriko Unibertsitatea (UPV/EHU), Sarriena auzoa z/g, 28940, Leioa \\ ${ }^{2}$ Instituto Biofisika (UPV/EHU, CSIC), Leioa, E-48940
}

LABURPENA: Zelulosa munduko biopolimerorik ugariena da, eta egiturak sortzeko erabiltzen du naturak. Ikerketa honetan, polimero honi buruzko ezagutza zabaltzeko zenbait kalkulu eta esperimentu proposatu dira. Propietate makroskopikoak propietate molekular eta molekula-arteko askoren nahasketaren ondorioa dira: horiek isolatzea eta gure mesederako erabiltzea da helburua. Laser-espektroskopia erabiliz, glukosa monomeroaren eta konplexuen ikerketa egin da, hauek gas eran izoztuta eta isolatuta daudelarik. Hemendik lortutako informazioa emaitza konputazionalekin zuzenean alderatu daitekeenez, kalkulu-metodorik egokiena aukeratu da. Azkenik, metodo teoriko honen bidez, zelulosaren kateak eta haien arteko elkarrekintzak argitu dira. Ikerketa honen bidez zenbait ezaugarri ikusi dira, haien artean $\beta$-glukosaren egitura zapalak hidrogeno lotura gehiago eta eraginkorragoak sortzeko duen gaitasuna duela.

HITZ GAKOAK: Gas fasea, espantsio supersonikoa, espektroskopia laserra, 3D egitura esleipena, kimika konputazionala, mekanika molekularra, ab-initio, DFT, energia askea, lotura energia.

ABSTRACT: Cellulose is the most abundant biopolymer in the world and nature uses it to create structures. In this study, various calculations and experiments have been proposed to expand knowledge about this polymer. A study of glucose monomer and complexes was performed by using laser spectroscopy, which is able to froze and isolate them in form of gas. Since the obtained information can be directly compared with the computational results, the most appropriate calculation method has been chosen. Finally, this theoretical method has unraveled the cellulose chains and their interactions. Through this research, it has been possible to distinguish the ability of the $\beta$-glucose planar structure to generate increasingly efficient hydrogen bonds.

KEYWORDS: Gas phase, supersonic expansion, laser spectroscopy, 3D structural assignment, computational chemistry, molecular mechanics, ab-initio, DFT, free energy, binding energy.

\footnotetext{
* Harremanetan jartzeko / Corresponding author: Imanol Usabiaga. Kimika Fisikoa Saila, Zientzia eta Teknologia Fakultatea, Euskal Herriko Unibertsitatea UPV/EHU, Sarriena auzoa z/g, 48940 Leioa. - i.usabiaga@outlook.es - https://orcid.org/00000002-1621-8536

Nola aipatu / How to cite: Usabiaga, Imanol; Parra, Maider; Insausti, Aran; Camiruaga, Ander; Veloso, Antonio; Fernández, José Andrés (2021). "Zelulosa biopolimeroaren propietate molekularrak argiratzen». Ekaia, 40, 2021, 259-271. (https://doi.org/10.1387/ekaia.21791).

Jasotze-data: 2020, ekainak 5; Onartze-data: 2020,abenduak 29.

ISSN 0214-9753 - elSSN 2444-3581 / (c) 2021 UPV/EHU
}

cc)(i) $\Theta$ Lan hau Creative Commons Aitortu-EzKomertziala-LanEratorririkGabe 4.0 Nazioartekoa lizentzia baten mende dago 
Imanol Usabiaga, Maider Parra, Aran Insausti, Ander Camiruaga, Antonio Veloso, José Andrés Fernández.

\section{SARRERA}

Zelulosa naturan aurkitzen den biopolimerorik ugariena da; izan ere, landare-zelulen horma osatzen duen osagai nagusia da. Arrazoi horregatik, makromolekula honen ekoizpena oso merkea da, eta horrek oso material interesgarria bilakatzen du. Gaur egun, zelulosaren erabilera oso hedatua dagoen arren, haren aparteko propietateen optimizazio-nahiak zientzialarien arreta piztu du, materialaren eraldaketa aproposak zeregin berriak betetzeko aukera ugari ematen baititu [1-3]. Hala ere, material berriak eratzeko, ezinbestekoa da materialen propietateen jatorri molekularra ulertzea: adibidez, haren propietate makroskopiko bat zenbait egitura molekularrekin erlazionatuta dago, eta hauek identifikatu eta ulertzea lagungarria da polimero horren ezaugarri makroskopiko hori gure mesedera moldatzeko.

Lan honetan, zelulosaren propietateak ezagutzeko, monomeroaren eta katearen zati txikien egonkortasuna eta molekularteko elkarrekintzak ikertu dira. Hauek zehazki deskribatzea lortuz gero, polimeroaren portaera makroskopikoa hobeto ulertzeko gai izango gara. Beraz, ikerketa hau aurrera eramateko zati txikienetatik (monomeroetatik) hasi eta atal handiagoen propietateak ikertzen jarraituko dugu.

Hasteko, zelulosaren monomeroa den $\beta$-glukosaren ikerketa egin da, eta molekula hau intramolekularki egonkortzeko dituen aukerak nagusiak determinatu eta esleitu dira. Bigarren urrats batean, haien konplexuak (bi molekulez edo gehiagoz osatutako egitura egonkorrak) eratu dira, molekulen arteko elkarrekintzen eraginak barne-molekularrek eragiten dituztenetatik bereizteko. Prozedura hau guztia gas fase berezi batean aurrera eraman da, espantsio supersonikoan, hain zuzen. Teknika berezi horrek molekula eta konplexuak isolatuta ikertzeko aukera emango digu, beste edozeren interferentziarik gabe. Gainera, aipatutako teknikak molekulak eta konplexuak oso hotz egotea eragiten du, solido eran egongo balira bezala, egitura egonkorrenean egonkortuta.

Hau guztia lortzeko, bereizmen masikoan oinarritutako laser-espektroskopia teknika erabili da. Teknika horren abantailetako bat da lortutako emaitzak datu konputazionalekin zuzenean aldera daitezkeela. Beraz, monomero eta dimeroen azterketa esperimentalaren ondorioz, haien propietateak ezagutzeaz gain, metodo konputazionalen zehaztasuna aztertzea ere posible da. Moldatutako prozedura konputazional hori oso erabilgarria izango da esperimentalki neurtu ezin dugun tamaina handiagoko polimero zatiak ikertzeko. Zelulosa polimeroaren zati handiago hauekin molekulabarneko eta molekularteko elkarrekintzak kalkulu teorikoz aztertuko ditugu.

\section{METODO KONPUTAZIONALAK}

Monomero eta dimeroaren azterketa konputazionala bilaketa konformazionalarekin hasiko da. Horretarako, zehaztasun baxua duten kalkulu- 
maila erabili ohi da; kalkulu horiek ez dute zertan zehatzak izan behar, haien eginkizun nagusia denbora laburrean egitura egonkorren aurretiazko zerrenda bat eratzea baita. Horretarako, mekanika molekularrean [4] (MM) oinarritutako metodoak eta sistema organiko eta biopolimeroentzat aproposak diren AMBER [5, 6], MMFFs [7] eta OPLS [8] parametrizatutako indar-eremuak erabili ohi dira. Modu horretan, monomero eta dimeroek aurkeztu ditzaketen zehaztasun baxuko egitura posible guztiak aurreikus daitezke. Ondoren, bigarren urrats batean, MM bidez lortutako egiturak maila altuagoko kalkulu mekaniko-kuantikoen bidez optimizatzen dira. Alde batetik ab-initio (MP2/6-311++G(d,p)) edo hasieratik Schrödinger ekuazioan oinarritutako kalkulu astunak eta DFT edo dentsitate elektronikoan oinarritutako $(\mathrm{M} 062 \mathrm{x} / 6-311++\mathrm{G}(\mathrm{d}, \mathrm{p}))$ metodoekin, hain zuzen. Metodo konputazional astun hauek informazio fidagarria emango digute egiturari eta egonkortasunari dagokienez. Bi metodo horien emaitzen arteko antzekotasuna eta lan honetan ikertutako sistemen tamaina handiagatik, DFT kalkuluen erabilera hautatu da ikerketan sakontzeko. Izan ere, ikertutako sistemaren tamaina handitzeak, hau da, atomo kopuru handiagoa izateak, metodo konputazional arinagoaren beharra eskatzen du.

Polimeroetan eragin handia duen propietate bat elkarrekintza intermolekularrak dira, hauek kateak beren artean zenbateko indarrarekin lotuta dauden esaten baitigute. Hala ere, informazio hau kalkulu konputazionalen bitartez lortzeko prozedura ez da erraza, eta dimerorik txikienak baino ezin dira zehaztasunez kalkulatu. Beste alde batetik, tenperaturaren eragina ere handia izan daiteke sistema hauetan. Hori kontuan hartzeko, optimizatutako egituren frekuentzien kalkulua erabili da, eta haien eta partizio funtzioen bidez konplexuaren egonkortasuna jakin daiteke tenperatura bakoitzean. Modu horretan, posible da lotura-energia askearen balioa molekulen tenperatura-tarte osoan determinatzea. Azkenik, lotura-energiaren balio zehatza eskuratzeko, dimeroaren energia erlatiboari monomero askeen energia erlatiboa kendu behar zaio.

Molekula baten propietateak jakiteko, haren energia potentzialaren gainazala (EPG) ezagutu behar da; baina, zer da hori? EPG molekula bakoitzaren mapa topografikoaren antzekoa da, han molekulak har ditzakeen egitura egonkor guztiak agertzen dira, aranak izango balira bezala. Mendi tontorrak energia maximoak dira, eta minimoak lotzen dituzten bideak, trantsizio-egoerak. Mapa topografiko horiek ezin dira beti grafikoki adierazi: gehienetan bi koordenatu baino gehiago alda daitezke molekularen barruan; horregatik, hurbilketak erabili behar dira. Gure kasuan glukosa monomeroaren EPG eraikitzeko, glukosak angelu diedro anitz aurkezten dituenez, honako hurbilketa hau burutu da: grafikoaren ardatz bakoitzari koordenatu bat esleitu ordez, minimoak irudikatu eta haien arteko energia minimoaren konbertsio-langa irudikatu da (ikusi 1. irudia a atala). 
Imanol Usabiaga, Maider Parra, Aran Insausti, Ander Camiruaga, Antonio Veloso, José Andrés Fernández.

Egituren esleipena egiteko, espektro teorikoaren simulazio-espektro esperimentalarekin alderatzen da. Kalkulu mekano-kuantikoetatik bibrazio frekuentziak lortuko ditugu; haien bidez, simulatutako espektro konputazionalak irudikatzeko gai izango gara, baina hori era egokian egiteko zenbait propietate kontuan izan beharko dira. Erabilitako metodo konputazionalek frekuentzien ebazpena egiteko hurbilketa harmonikoa erabiltzen dutenez, bibrazio-frekuentziei anharmonizitate zuzenketa-faktore bat egokitu zaie (OH: 0.9384 eta $\mathrm{CH}$ : 0.953); faktore horiek erreferentzia molekulen eta kalkuluen bidez lortu dira. Jatorri kuantikodun frekuentzien zabalera funtzio lorentziar baten bidez islatu da, eta laserraren efektua simulatzeko, funtzio gausstar baten konboluzioa atxikitu zaio.

Amaitzeko, kateen eta kateen arteko elkarrekintzak ikertzeko, datubase kristalografikoaren (CCDC) egiturak hartu dira [9]. Egitura erraldoi hauetatik atal nabarmenen egonkortasuna DFT kalkuluen bidez kudeatu da. Kasu hauetan, hartutako molekulen tamaina dela eta, aurreko kalkuluetan erabilitako DFT metodoei kalkulu-maila murriztu behar izan zaie (M062x/ 6-31+G(d)), kalkuluen konputazio-denbora bideragarria izan dadin.

\section{METODO ESPERIMENTALAK}

Glukosa monomero eta dimeroaren azterketa konformazionala egiteko, bereizmen masikoan oinarritutako laser-espektroskopia teknika esperimentala erabili da; horretarako, eraldatutako JORDAN T.O.F. masa-espektrometroa erabili da [10-12]. Teknika horrek, espantsio supersonikoa erabiltzen du molekulak edo konplexuak gas eran izoztu eta isolatzeko. Egoera hori lortzeko, $10 \mathrm{~Hz}-\mathrm{ko}$ frekuentzian (General Valve) lan egiten duen pultsuzko balbula erabili da, hura irekitzean gas pultsu edo txorrota batek glukosa molekulak bultzatuz, izoztu, konplexuak eratu eta espektrometrora garraiatu ditu. Han, laser ultramorearen (UM) bidez, bi fotoien absortzioa eragin da molekulak eta konplexuak ionizatuz: teknika hau «Resonance Enhanced Multi Photon Ionization» (REMPI) laser-teknika izenez ezagutzen da. Teknika honen funtzionamendua lehengo fotoiaren absortzioak kitzikatutako maila elektro-bibrazional baten energiarekin bat egitean absortzioaren probabilitatea asko handitzean datza, eta horren ondorioz, kitzikatuko molekulen kopurua ere handiagoa izango da. Bigarren fotoiak, kitzikatuta dauden molekulen kopuruaren arabera, ioiak eratuko ditu. Fenomeno horren ondorioz, lortutako seinalea lehenengo fotoiaren absortzioaren araberakoa izango da. Metodologia esperimental horri esker, monomero edo konplexu bakoitzarentzat bananduta erresoluzio altuko espektro elektronikoa lortuko dugu. Zenbait kasutan REMPI teknikaren bidez lorturiko trantsizio elektronikoak desberdinak dira isomero konformazionalen artean. Aipatutako desberdintasuna gertatzen denean konformero bakarraren espektro elektronikoa egin daiteke. Egituraren esleipena egiteko, erresonantzia bikoitzeko (bi laser) teknika erabili da, infragorrizko (IR) eta UM -laserren ar- 
teko konbinazioa, kasu honetan. Erresonantzia bikoitzeko teknika horren izena «Resonance Ion Dip Infrared Spectroscopy» (RIDIRS) da. Lehen urrats batean, UM -laserra isomero baten trantsizio elektro-bibrazional batean sintonizatzen da, eta hau baino 100-150 ns lehenago jarritako IR-laser baten bidez, UMlaserraren ioien seinale konstantea despopulatuko da. IR-laserraren energiaren ekorketaren bidez, IR-espektroa lortuko da, monomero edo konplexu bakoitzerako bananduta.

\section{EMAITZAK ETA EZTABAIDA}

\section{1. $\beta$-Glukosaren $(\boldsymbol{\beta}-\mathrm{G})$ ikerketa esperimentala eta konputazionala}

Zelulosa $\beta$-glukosa monomeroz osatuta dagoen kate molekularra da. Sarreran aipatu den moduan, material berriak eratzeko, ezinbestekoa da haien molekulen egitura-propietateak ulertzea. Horregatik, kasu hauetan monomeroen egitura eta propietateak aztertuko dira. Alde batetik, kalkuluak erabiliz, $\beta$-Glukosa EPG kalkulatuko dugu, eta ondoren, esperimentalki $\beta$-fenil-glukosa neurtuko dugu. Laser-espektroskopiaren bidez neurtzeko kromoforoa den talde funtzionala behar du; izan ere, azken horrek lehen fotoiaren absortzioa ahalbidetzea du helburutzat. Kasu honetan, glukosa molekulari lehenengo oxigenoan fenilo taldea erantsi zaio, eta $\beta$-fenil-glukosa molekula lortu da, zeina neurtzeko gai izango garen. $\beta$-glukosaren energia potentzial gainazalaren (EPG) hurbilketak molekulak hiru konformero bereziki egonkor ( $\beta$-G-01, $\beta$-G-02 eta $\beta-\mathrm{G}-03)$ aurkezten ditu, 1.a irudian ikus daitekeen moduan. Aipatutako hiru konformeroak bat datoz mikrouhinen espektroskopiaren bidez egindako beste ikerketekin [13]. 1.b irudiari dagokionez, laser-espektroskopiaren bidez egindako $\beta$-fenil-glukosaren infragorri-espektroaren esleipena ikus daiteke. Irudian bertan, ikusitako hiru egituren ( $\beta$-PG-01, $\beta$-PG-02 eta $\beta$-PG-03) espektro esperimentala eta DFT kalkuluen bidez lortutako simulazioaren arteko konparaketa irudikatu da, non kalkulu teorikoak eta datu esperimentalak bat datozela ondoriozta daitekeen. Egindako esleipena aldez aurretik egindako ikerketen berdina da [14].

Hainbat ondorio atera daitezke. Alde batetik, simulazio teorikoak aurrera eramateko hautatutako kalkulu-maila egokia dela, lortutako datuak emaitza esperimentalekiko baliokideak baitira. Egitura egonkorrenei dagokienez, esleitutako hiru konformazioen arteko desberdintasun bakarra hidroximetilo taldearen kokapena dela ikus daiteke, hidroxilo taldeak $\mathrm{O} 4$ edo O5 atomoarekin hidrogeno-lotura intramolekularra duelarik. Aipagarria da talde hidroxilo guztiak haien artean hidrogeno-lotura kooperatiboen sekuentzia eratzen dutela eta sekuentzia honetan hidroxilo bakar baten noranzkoaren aldaketak alboko hidroxiloengan eragingo duela. Glukosak aurkeztutako hidrogeno-lotura intramolekularrak egonkortze-faktore nagusiak 
Imanol Usabiaga, Maider Parra, Aran Insausti, Ander Camiruaga, Antonio Veloso, José Andrés Fernández

direla azpimarratu daiteke. Beste era batera esanda, glukosa isolatua dagoenean egitura egonkorrenen hidroxilo taldeek molekula barnealderako norabidea hartzen dute. Hala ere, konplexuak eratzean egiturak egonkortzeko joera horren aldaketa gerta liteke. Hori gertatzeko, egiturak egonkortzen dituzten elkarrekintza intermolekularak indartsuagoak izan beharko lirateke intramolekularrak baino.

Azkenik, $\beta$-G monomeroa berezia egiten dituen ezaugarriak aipatzea beharrezkoa da. Izan ere, molekula honen ziklohexano egituran edo, beste era batera esanda, piranosa eraztunari lotutako hidroxilo-talde guztiak kokapen ekuatorialean aurkitzen dira (ziklohexanoan bi posizio daude: ekuatoriala edo eraztunaren planoan, eta axiala edo planoarekiko perpendikular eran). Horri esker, molekula honek gainerako karbohidratoak baino egitura lauagoa du, eta horrek zelulosako kate konplexua eratzean nolabait eragin dezake.
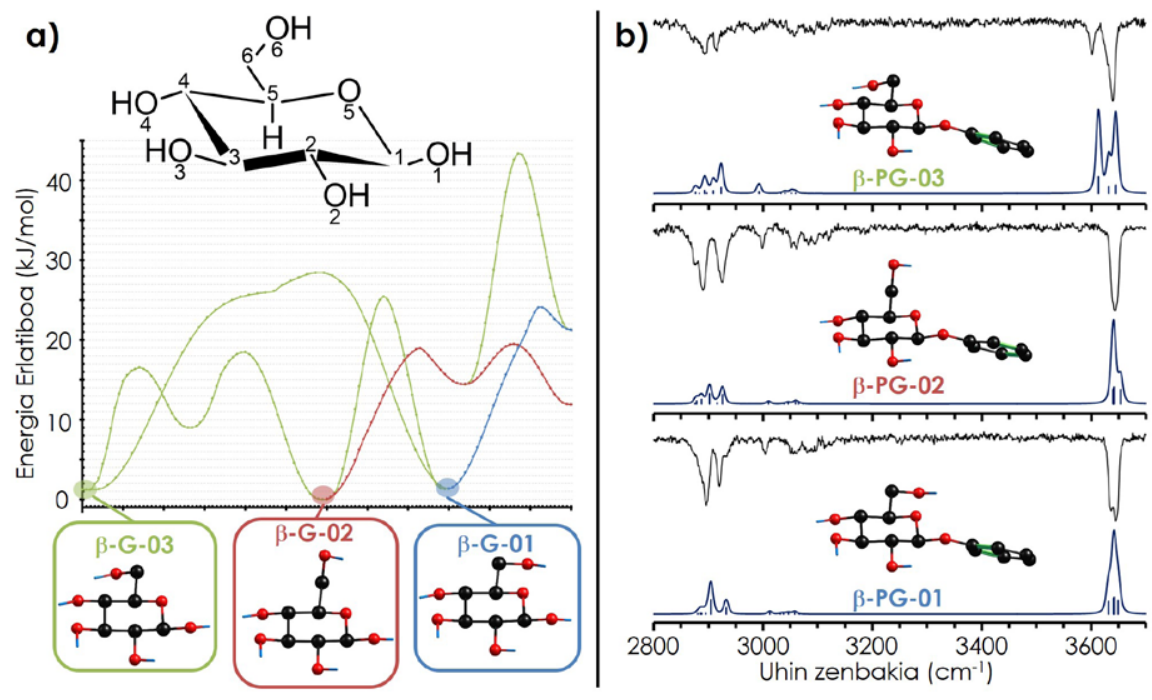

1. irudia. a) $\beta$-glukosaren $(\beta-G)$ EPG aurkezten da, atal hau egitura egonkorrenei dagokie. b) atalean fenil- $\beta$-glukosaren $(\beta-P G)$ espektro esperimentala eta konputazionalaren konparaketa aurkezten da; espektro bakoitzari esleitutako egitura erakusten da.

\subsection{Glukosa monomeroen arteko lotura indarraren determinazioa}

Atal honetan, glukosen arteko elkarrekintzak sortzeko gaitasuna aztertu da. Gas eran dauden bi molekula lotuz sorturiko unitatea ikertuz egingo da; horri konplexu edo dimero deituko diogu. $\beta$-G-ren propietateak determinatzeko, $\beta-\beta$ eta $\beta-\alpha$ anomeroen arteko hainbat konplexu desberdin eratu dira 
gas eran [15]. Glukosa bi anomero desberdinetan aurkitu daiteke $\alpha$ edo $\beta$ anomeroetan; hori lehenengo oxigenoaren kokapenarekin erlazionatuta dago, $\alpha$ axial eran kokatuta du eta bestetik $\beta$ anomero ekuatorial eran kokatuta. Zelulosa soilik $\beta$ anomeroaz osatuta dago, baina interesgarria da haien elkarrekintzak alderatzea zelulosaren berezitasunak ulertzeko. Anomero horien arteko konplexuak fenilatutako glukosaren eta metilatutako glukosen konbinaketaz sortuko dira. Hiru molekula desberdin erabiliko dira, bakoitzak muga batzuk baititu: alde batetik, fenilatutako glukosan soilik $\beta$-anomeroak izango dugu, kromoforoak ionizazioa ahalbidetuko digu, baina konplexua eratzean feniloak elkarrekintzan interferentzia eragin dezake. Metilatutako $\alpha$ eta $\beta$ glukosek banaka anomeroak ikertzea ahalbidetuko digu, metilatu gabe biak aldi berean izango genituzke eta, baina kromofororik ez dutenez fenilatutako glukosarekin eratu beharko dira konplexuak. $\alpha$ - $\alpha$ glukosen arteko elkarrekintzen azterketari dagokionez, lagina esperimentalki neurtzeko eskuragarri ez izateak soilik konputazionalki aztertzea posible utzi digu. Gas eran eratutako konplexuak $\beta$-PG eta metilatutako $\alpha / \beta$-glukosak $(\alpha / \beta$-MG) isolatzean sortu dira, horrela ikertzen ari den monomeroa zehatz-mehatz zein den jakitea posible da. 2.a irudian eratutako dimero desberdinen espektro esperimentalak eta haien esleipena ikus daitezke. Alde batetik, fenil- $\beta$-glukosaren ( $\beta-P G)$ eta metil- $\beta$-glukosaren ( $\beta$-MG) arteko dimeroa dugu ( $\beta-\beta$ dimeroa). Dimero horrek aurkezten duen egitura nahiko simetrikoa da. Kasu honetan, glukosa unitateen artean molekularen bi ertzetan hidrogeno-lotura bikoitza eratzen da, guztira lau hidrogeno-lotura intermolekular direlarik. Egituren esleipena egitea nahiko tribiala da, kontuan hartuz esleituriko konplexurik egonkorrena gainerako egiturak baino $10 \mathrm{~kJ} / \mathrm{mol}$ egonkorragoa dela. Horren ondorioz, egitura ezegonkorragoak ikusteko probabilitatea oso urria da. Zenbait kasutan, gerta daiteke O1-tik lotutako metiloak eta feniloak molekularteko elkarrekintzetan parte hartzea, eta, hortaz, interferentzia bat bilakatzea. Hala ere, fenilatu eta metilatu gabeko molekulen kalkulu teorikoekin konparaketak eginez, interferentziarik eragiten ez dutela egiazta daiteke. Beste aldetik, gas eran isolatutako $\beta-\mathrm{PG}$ eta $\alpha-\mathrm{MG}$ arteko dimeroa dugu ( $\alpha-\beta$ dimeroa). Honen espektro esperimentala aztertuz, bere esleipena egiteko bi egitura beharrezkoak dira. Egokitutako lehengo egitura, kalkulu kimiko-kuantikoen egituretatik egonkorrenari dagokio. Konformero honetan (2. irudia) glukosa-unitateen arteko bi hidrogeno-lotura gertatzen dira, baita $\alpha$-MG-ren piranosa eta $\beta$-PGren feniloaren arteko Van der Waals elkarrekintzak ere. Feniloaren presentziak lehenengo isomero honetan interferentzia nabarmena eragiten du; izan ere, molekularen egitura baldintzatzen du. Beste alde batetik, esleipena egiteko beharrezkoa den bigarren isomeroa tenperatura altuagoan aurkitzen den konformerorik egonkorrena da. Konplexu honetan, aldiz, feniloak ez du interferentziarik eragiten. Esleitutako bigarren isomeroak hiru hidrogeno-lotura egonkortzaile indartsu aurkezten ditu. Hau guztia kontuan izanda, $\beta-\beta$ lotura eraginkorragoa dela ondoriozta daiteke. Horren arrazoia $\alpha$-anomeroaren lehen talde-hidroxiloaren kokapen axiala da, zeinak aipatutako anomerok 
Imanol Usabiaga, Maider Parra, Aran Insausti, Ander Camiruaga, Antonio Veloso, José Andrés Fernández.

eratu ditzakeen hidrogeno-lotura indartsuen kopurua baldintzatzen duen. Ondorioz, $\alpha$-anomeroaren egitura ez da $\beta$-anomeroarena bezain laua, eta lau hidrogeno-lotura intermolekular eratzeko aukera galtzen du.

$\beta-\beta$ anomeroen arteko loturen eraginkortasuna egiaztatzeko asmoz, hainbat kalkulu teoriko egin dira glukosaren, metilatutako glukosaren eta fenilatutako glukosaren arteko anomeroen konbinaketak eginez. Honako dimeroen lotura-indar hauek kalkulatu dira: $\beta-\beta, \beta-\alpha$ eta $\alpha-\alpha$. 2.b irudiko grafikoan dimero mota bakoitzaren egiturarik egonkorrenen lotura-energiak irudikatu dira, metiloak eta feniloaren bidez lotzen diren egiturak kendu direlarik. Grafikoaren interpretaziorako, jakin beharra dago loturaindarra zenbat eta negatiboagoa izan orduan eta indartsuagoa izango dela lotura. Hau guztia esanda, eta grafikoan behatzen den joera kontuan hartuz, $\beta-\beta$ lotura beste lotura motak baino egonkorragoa dela ondoriozta daiteke.
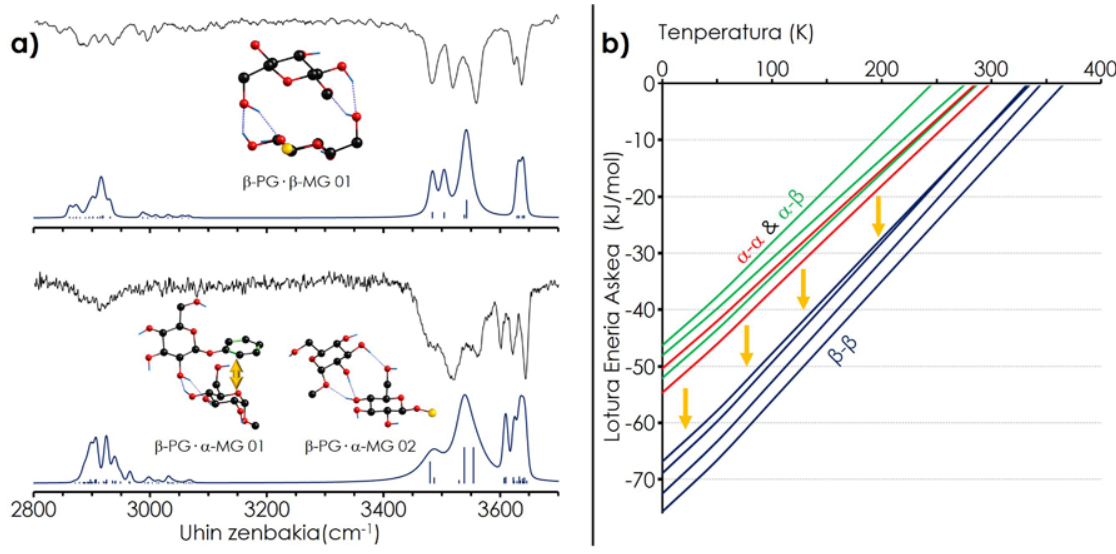

2. irudia. a) fenil- $\beta$-glukosa $\cdot$ metil- $\beta$-glukosa $(\beta-\mathrm{PG} \cdot \beta-\mathrm{Mg})$ eta fenil- $\beta$-glukosametil- $\alpha$-glukosa ( $\beta$-PG· $\alpha-\mathrm{Mg}$ ) konplexu esperimentalen esleipena simulazio konputazionalen alderaketaren bidez b) lotura energia $\alpha-\alpha, \alpha-\beta$ eta $\beta-\beta$ glukosa dimeroen artean grafikoki adierazita tenperaturaren aurrean.

Beraz, emaitza esperimentalak eta egindako kalkuluak ikusita, $\beta-\beta$ anomeroen arteko elkarrekintza eraginkorragoa dela egiazta daiteke. Aurretik aipatu den bezala, horren arrazoia $\beta$ anomeroak aurkezten duen egitura lauan dago, zeinak molekulen arteko hidrogeno-loturen sekuentzia luzeagoa eratzea ahalbidetzen duen.

\subsection{Zelulosa katearen egonkortasunaren ikerketa konputazionala}

Monomeroen propietateak eta haien arteko elkarrekintzak fase isolatuan aztertu ondoren, hurrengo urratsa glukosa unitateak polimero katean txerta- 
tuta duen eragina ikertzea da. 3 . irudian ikus daitekeen moduan, $\beta$-glukosa piranosa eraztunak ${ }^{1} \mathrm{C}_{4}$ egitura du (katean dauden glukosak lehenengo eta laugarren oxigenoen bidez lotuta daudela adierazten $\mathrm{du}$ ), eta polimeroa eratzean monomeroek egitura hau mantentzen dute. Hala ere, katea zenbait egitura desberdin hartzeko gai izango da. Horretarako, bi aldagai nagusi daude: glukosen arteko bata bestearekiko posizioa (txandakatuta eta ez-txandakatuta) eta glukosen arteko oxigeno lotura kobalentearen tolesdura. Txandakatuta dauden glukosetatik hasita, glukosa-monomeroez osatutako katearen kristal-egiturak (a eta $b$ egiturak) [9] aztertu dira. Haien arteko desberdintasun bakarra hidrogenoen kokapena da. Nahiz eta kasu bietan hidrogeno-lotura intramolekular kopurua berdina den, a-egituraren kasuan $(\mathrm{O} 6 \mathrm{H} \rightarrow \mathrm{O} 2)$ hidrogenoaren kokapenak egonkortasun-maila altuagoa lortzea eragiten du b kasuan baino $(\mathrm{O} 2 \mathrm{H} \rightarrow \mathrm{O} 6)$, hau baita bien arteko desberdintasun bakarra. Txandakatutako multzo honen barruan hirugarren egitura bat kalkulatu da, zeinari hidrogeno-lotura bat murriztu zaion hidroxilo baten biraketaren bitartez. Aldaketa horien ondorioz, katea nabarmenki ezegonkortu dela ikus daiteke, eta gainera, kimika kuantikoaren bidez egindako optimizazio-prozesuak egitura kristalografikoarekin alderatuta oso desberdina den egitura eratu du. Horrekin ondoriozta daiteke kristala eratzeko a eta b egiturek aurkeztutako hidroxiloen sekuentziak ezinbestekoak direla.

Ez-txandakatuei dagokienez, haien egonkortasuna kalkulatu da, 3 egitura desberdin eraikiz eta energiaren optimizazioa burutuz. Kateak lehengo txandakatutako kateetan oinarritzen dira, kristal 1 katea hartu da, eta glukosa monomeroak biratu dira txandakatuak ez egoteko. Txandakatuta daudenean bi hidrogeno lotura dituzten egiturak egonkorrenak direnez, hemen ere bi hidrogeno lotura eratu dezaten bideratu dira hidroxiloak $(\mathrm{O} 3 \mathrm{H} \rightarrow \mathrm{O} 2$ eta $\mathrm{O} 6 \mathrm{H} \rightarrow \mathrm{O} 5)$, eta gero kalkuluen bidez egiturak optimizatu dira. Glukosa monomeroak txandakatuta ez daudenez, oxigeno lotzailearen tolesteko erak norabide bera hartzen du. 3. irudian ikus daitekeen moduan, katearen lautasuna desagertu egiten da. Izan ere, $\mathrm{d}$ eta $\mathrm{f}$ kasuetan katea kiribildu egiten da. Efektu hori kudeatzeko, e egitura egin da, molekula honetan oxigenoaren tolesteko era txandakatu da, hau da, lehengo eta hirugarren oxigenoek toleste negatiboan edo gorantz mantendu dira, eta bigarren oxigenoan toleste positiboan edo berantz eragin da. e egituran egindako tolesdura nahasketa horrek egitura sinusoidala hartzera bultzatu du. Irudian beha daitekeen moduan, txandakatu gabeko glukosa familiaren barruan egiturarik egonkorrena d-egitura da.

Kristalaren antza hartu ahal duten kateak lauak izan behar dutela ondoriozta daiteke, eta beraz, haien itxura kontuan hartu beharko da kateen arteko ikerketa aurrera eramateko. Beste alde batetik, aipagarria da talde hidroxiloen norabidearen aldaketa txikiek eta glukosen ez-txandakatzeak katearen lautasuna galtzea eragiten duela. Katearen egiturak eratutako materialaren kristal eta amorfo ataletan eragina izango du, eta, noski, propietateetan islatuko da. 
Imanol Usabiaga, Maider Parra, Aran Insausti, Ander Camiruaga, Antonio Veloso, José Andrés Fernández

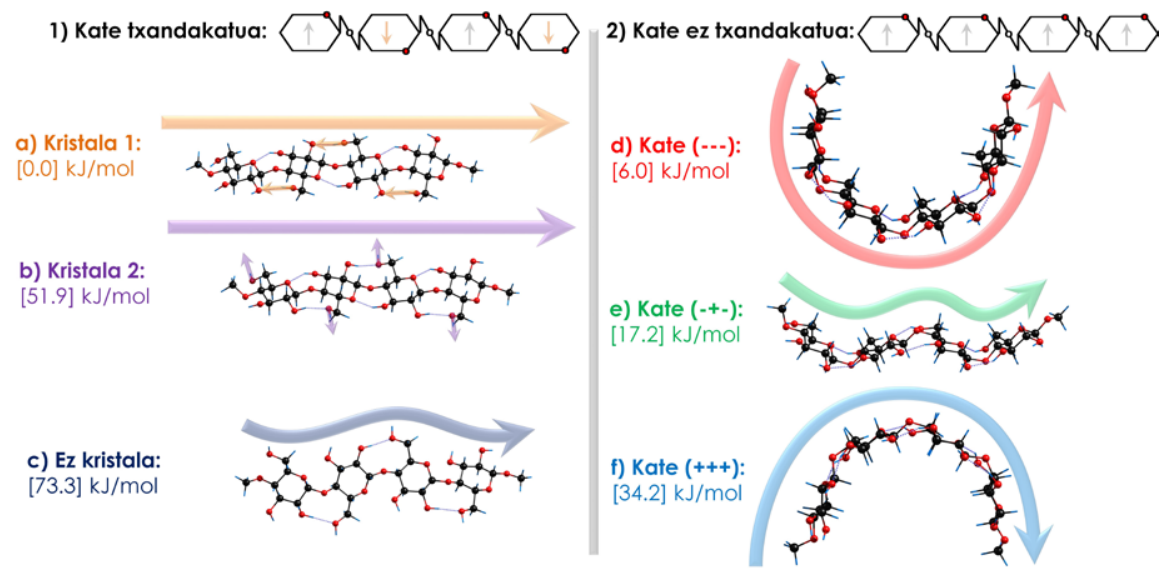

3. irudia. Kristalean aurkitutako egituretan («The Cambridge Crystallographic Data Centre» (CCDC))[9] oinarritutako lau monomeroez osatutako kate linealen egituraren optimizazioa.

\subsection{Zelulosa kateen arteko elkarrekintzaren ikerketa konputazionala}

Azkenik, kateen arteko elkarrekintza ikertu da. Kasu honetan, kristaletik lortutako egitura erabili da hidrogeno-loturen sekuentzien egonkortasuna ikertzeko. Horretarako, bi optimizazio-kalkulu mota desberdin burutu dira: (i) oxigeno eta karbono atomoen posizioa finko mantenduz eta (ii) haien posizioa aske utziz. Bi egoera horien kalkuluen emaitzen bidez, posible izan da hidrogeno-loturen sekuentzien eraginkortasuna ikustea. Horretarako, hiru sekuentzien kalkuluak egin dira: lehen biak 3. irudian erabilitako a eta $\mathrm{b}$ egiturei dagokie eta eraikitako hirugarren egitura bat (c). 4. irudian ikus daitekeenez, aurreko kateen ikerketan ikusi den bezala, egiturarik egonkorrena (Kristala 1 egitura) kasu honetan ezegonkorrena da. Kristala 1 egituran energiaren optimizazio-prozesuan atomoak aske uzteak egitura nabarmenki deformatzen du. Beste alde batetik, Kristala 2 egitura egonkorrena dela beha daiteke, bai $\mathrm{C}$ eta O-atomoak finko zein aske utziz. Izan ere, nahiz eta atomoak aske utzi, DFT optimizazioan pairatutako deformazioa oso txikia da. Horrek, sekuentziarik egokiena dela adierazten du. Kasu honetan, hidrogeno-loturek bai katearen barneko eta kateen arteko elkarrekintzak ere maximizatzen dituzte. Hirugarren egiturak (Kristala 3) tarteko egonkortasuna eta deformazioa aurkezten duela ikus daiteke.

4.3. atalean ikusitako kateen egonkortasuna eta 4.4. atalean ikertutako kateen arteko elkarrekintza alderatuz, zenbait ondorio atera daitezke. Alde batetik, kristala sortzeko prozesuan Kristala 1 egitura (a-egitura 
3. irudian) egokiena dela esan daiteke, kateak aske dauden bitartean barne-molekular eran egonkortuta baitago. Aldiz, kateak konbinatzean barne-molekular eran desegonkortzea onuragarria da baldin eta molekulen arteko elkarrekintza indartzeko balio badu; fenomeno hori Kristala 2 egituran ikusten da.

a) Krisłala 1:

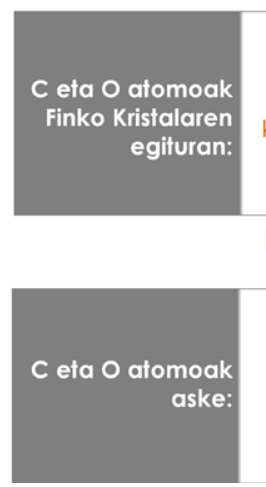

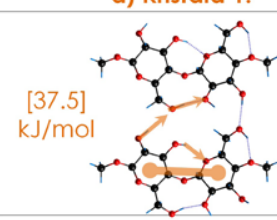

Deformazio Altua

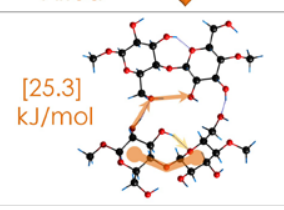

b) Kristala 2:

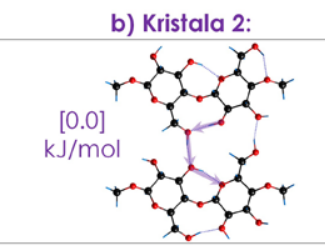

Deformazio
Txikia Txikia

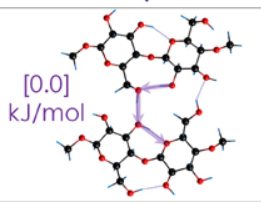

c) Kristala 3:

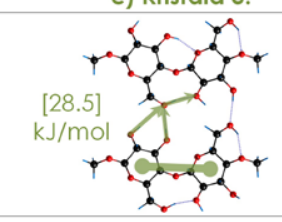

4. irudia. CCDC datu basean lortutako zelulosa kristalinoaren egitura oinarrituta[9] hiru hidrogeno lotura antolaketa desberdinen egitura optimizazioa.

\section{ONDORIOAK}

Ikerketa honetan glukosa monomeroaren egonkortze barne-molekularra eta molekulartekoa aztertu da, bai kalkulu kuantikoaren bai metodo esperimentalen bidez. Kalkulu teorikoak erabilita, tamaina handiagoko zelulosa-oinarria duten sistemen ereduak proposatu dira. Posible izan da $\beta$-glukosaren zenbait ezaugarri azpimarratzea. Alde batetik, talde hidroxilo guztiak kokapen ekuatorialean egoteak egitura lauak eragiten dituela eta joera hori hidrogeno-loturen sekuentziaren menpe dagoela behatu da. Gainera, hidrogeno-loturen kopurua egonkortze-faktore bakarra ez dela ikusi da: lotura bakoitzaren indarra lotura kopurua bezain garrantzitsua da, adibidez. Beste aldetik, lortutako emaitza esperimental eta teorikoak alderatuz, aukeratutako kalkulu-maila egokia dela ondoriozta daiteke. Modu horretan, datu esperimentalak mekanika molekularrak erabiltzen dituen indar-eremuak hobetzeko erabil daitezkeela frogatu da. Amaitzeko, lan honen bitartez, frogatu da egokia dela, laser-espektroskopia espantsio supersonikoarekin eta kalkulu konputazionalekin konbinatuta, material berrien diseinuan lagundu dezakeen teknika, zeren (eta) gai baita molekulen egitura eta propietate intrintsekoak zehaztasun handiz determinatzeko. 
Imanol Usabiaga, Maider Parra, Aran Insausti, Ander Camiruaga, Antonio Veloso, José Andrés Fernández.

\section{ESKER ONAK}

Eskerrak ematen dizkiogu MINECOri (PGC2018-098561-B-C21), Eusko Jaurlaritzari (IT1162-19) eta UPV/EHUri (PPG17/10, GIU18/207), laguntza ekonomikoarengatik. M.P.-k, A.I.-k eta A.C.-k eskertzen dute Eusko Jaurlaritzatik jasotako laguntza ekonomiko pre-doktoralarengatik eta I.U. (UPV/EHU) Euskal Herriko Unibertsitateak emandako laguntza ekonomiko post-doktoralarengatik. Azkenik, eskerrak SGIKER (UPV/ EHU) konputazio eta laser zerbitzuari ere.

\section{BIBLIOGRAFIA}

[1] ABUSHAMMALA H.; MAO J. 2019. «A Review of the Surface Modification of Cellulose and Nanocellulose Using Aliphatic and Aromatic Mono- and Di-Isocyanates». Molecules 24, 2782-2800.

[2] WANG H.; HE J.; ZHANG M.; CHIU TAM K.; NI P. 2015. «A new pathway towards polymer modified cellulose nanocrystals via a "grafting onto" process for drug delivery». Polymer Chemistry 6, 4206-4209.

[3] ROY D.; SEMSARILAR M..; GUTHRIE J. T.; PERRIER S. 2009. «Cellulose modification by polymer grafting: a review». Chemical Society Reviews 38, 2046-2064.

[4] MOHAMADI F.; RICHARDS N. G. J.; GUIDA W. C.; LISKAMP R.; LIPTON M.; CAUFIELD C.; CHANG G.; HENDRICKSON T.; STILL W. C. 1990. «Macromodel-an Integrated Software System for Modeling Organic and Bioorganic Molecules Using Molecular Mechanics». Journal of Computational Chemistry 11(4), 440-467.

[5] CASE D. A.; CHEATHAM T. E.; DARDEN T. O. M.; GOHLKE H.; LUO, R. A. Y.; MERZ K. M.; ONUFRIEV A.; SIMMERLING C.; WANG B.; WOODS R. J. 2005. «The Amber Biomolecular Simulation Programs». Journal of Computational Chemistry 26(16), 1668-1688.

[6] KIRSCHNER K. N.; YONGYE A. B.; TSCHAMPEL S. M.; GONZÁLEZ-OUTEIRIÑO J.; DANIELS C. R.; FOLEY B. L.; WOODS R. J. 2008. «GLYCAM06: A Generalizable Biomolecular Force Field. Carbohydrates». Journal of Computational Chemistry 29(4), 622-655.

[7] HALGREN T. A. 1996. «Merck Molecular Force Field. I. Basis, Form, Scope, Parameterization, and Performance of MMFF94». Journal of Computational Chemistry 17(5-6), 490-519.

[8] BANKS J. L.; BEARD H. S.; CAO Y.; CHO A. E.; DAMM W.; FARID R.; FELTS A. K.; HALGREN T. A.; MAINZ D. T.; MAPLE J. R.; ET AL. 2005. «Integrated Modeling Program, Applied Chemical Theory (IMPACT)». Journal of Computational Chemistry 26(16), 1752-1780.

[9] NISHIYAMA Y.; LANGAN P.; CHANZY H. 2002. «Crystal Structure and Hydrogen-Bonding System in Cellulose I $\beta$ from Synchrotron X-ray and 
Neutron Fiber Diffraction». Journal of the American Chemical Society 124, 9074-9082.

[10] BERMEJO I. A., USABIAGA I., COMPAÑÓN I., CASTRO-LÓPEZ J.; INSAUSTI A.; FERNÁNDEZ J. A.; AVENOZA A.; BUSTO J. H.; JIMÉNEZBARBERO J.; ASENSIO J. L.; PEREGRINA J. M.; JIMÉNEZ-OSÉS G.; HURTADO-GUERRERO R.; COCINERO E. J.; CORZANA F. 2018. «Water Sculpts the Distinctive Shapes and Dynamics of the Tumor-Associated Carbohydrate Tn Antigens: Implications for Their Molecular Recognition». Journal of the American Chemical Society 140(31), 9952-9960.

[11] USABIAGA I.; GONZALEZ J.; ARNAIZ P. F.; LEON I., COCINERO E. J.; FERNANDEZ J. A. 2016. «Modeling the tyrosine-sugar interactions in supersonic expansions: glucopyranose-phenol clusters». Physical Chemistry Chemical Physics 18, 12457-12465.

[12] CAMIRUAGA A.; USABIAGA I.; INSAUSTI A.; LEON I.; FERNANDEZ J. A. 2017. «Sugar-peptidic bond interactions: spectroscopic characterization of a model system». Physical Chemistry Chemical Physics 19, 12013-12021.

[13] ALONSO J. L.; LOZOYA M. A., PEÑA I., LÓPEZ J. C., CABEZAS C.; MATA S.; BLANCO S. 2014. «The conformational behaviour of free Dglucose-at last». Chemical Science 5, 515-522.

[14] TALBOT F.; SIMONS J. P. 2002. «Sugars in the gas phase: The spectroscopy and structure of jet-cooled phenyl $\beta$-D-glucopyranoside». Physical Chemistry Chemical Physics 4(15), 3562-3565.

[15] USABIAGA I.; GONZÁLEZ J.; LEÓN I.; ARNAIZ P. F.; COCINERO E. J.; FERNÁNDEZ J. A. 2017. «Influence of the Anomeric Conformation in the Intermolecular Interactions of Glucose». The Journal of Physical Chemistry Letters 8, 1147-1151. 
